\title{
El municipio brasilero y sus competencias en la esfera internacional $(*)$
}

\section{POR MARTÍN CANEPA $(* *)$}

\begin{abstract}
Sumario: I. Introducción.- II. Organización político-administrativa del Brasil.- III. Competencia municipal para celebrar tratados y asociarse.- IV. El municipio como actor en la esfera internacional.V. Conclusión.- VI. Bibliografía.
\end{abstract}

Resumen: el derecho que surge de los distintos modelos de integración regional ha cobrado en los últimos años un impulso sumamente relevante en el ámbito latinoamericano. Distintas organizaciones como el caso del Mercosur, del cual Brasil es parte, han logrado un amplio desarrollo a través del trabajo de los distintos Estados miembros. En este camino de desarrollo progresivo del derecho de la integración, el rol de los municipios resulta de vital importancia, ya que estas entidades se encuentran en el estrato más cercano a la población dentro de la pirámide organizacional de un Estado. En este sentido, es posible realizar un estudio de las competencias municipales en la esfera internacional, en la cual su participación se hace más evidente dentro del ámbito de la integración regional.

Palabras claves: derecho - integración - Brasil - municipios

\section{The Brazilian municipality in the regional integration}

Abstract: the law that arises from the different models of regional integration has gained in the last years an extremely important impulse in Latin America. Different organizations such as the case of Mercosur, of which Brazil is a part, have achieved a broad development through the work of the different States parties. In this path of

$(*)$ El presente artículo es producto del trabajo de investigación desarrollado como miembro del proyecto Decyt 1022 (UBA) 2010/2012: "Bases jurídicas para la inserción del municipio como actor en el proceso de integración del Mercosur". Facultad de Derecho, Universidad de Buenos Aires (UBA).

(**) Abogado, Universidad de Buenos Aires (UBA). Jefe de Trabajos Prácticos, Derecho Internacional Público y Derecho de la Integración, Facultad de Derecho, Universidad de Buenos Aires. 
progressive development of the law of Integration, the role of the Municipalities is of vital importance, since these entities are the closest to the population within the organizational pyramid of a State. In this sense, it is possible to carry out a study of municipal competences in the international sphere, in which their participation becomes more evident within the scope of regional integration.

Keywords: law - integration - Brazil - municipalities

\section{Introducción}

El objetivo del presente trabajo consiste en poder determinar cuál es el alcance de las competencias que poseen los municipios en Brasil en la esfera internacional y en particular en relación con los procesos de la integración regional, como, por ejemplo, el Mercosur. Estos procesos se relacionan con la cooperación, la armonización y la realización de políticas comunes en distintos ámbitos de manera tal de lograr una visión conjunta de los problemas que son comunes a varios Estados y llevar a cabo diversas políticas para resolverlos y fortalecer distintos aspectos de la estructura estatal, como la economía, la libre circulación de bienes, servicios y capitales, la cultura, la política migratoria, la adopción de medidas de política exterior, entre otras. Como sostiene Pizzolo (2002): "la integración solo puede actuar frente a una diversidad de espacios sociales, uniéndolos a un todo" (p. 26).

El municipio es la unidad más pequeña dentro de la esfera estatal. La descentralización de funciones en un Estado federal como Brasil encuentra en las entidades municipales uno de los actores más relevantes de los procesos de integración en los cuales se halla inmerso el Estado federal. El fundamento de esta afirmación radica en el hecho que más allá de los objetivos generales, de los principios e ideas fundacionales plasmados en los tratados que dan vida a los distintos procesos de integración, el fin último de estos consiste en que la vida de los individuos se vea modificada, que su realidad misma perciba los cambios que produce el hecho de estar inmersos en un proceso de integración. De todas las entidades descentralizadas que posee un Estado federal, los municipios representan la unidad que más cerca se encuentra de la población, es el ámbito donde los individuos pueden llevar sus reclamos en una primera instancia y donde ven reflejadas en forma directa las políticas que desarrolla el gobierno municipal. Por esta razón, resulta importante estudiar la existencia y el alcance de las facultades que poseen los municipios en relación con la integración regional.

En primer lugar, haremos una breve referencia a la organización territorial y a la forma de gobierno de Brasil, para luego adentrarnos en el análisis de los textos constitucionales. Nos concentraremos en los artículos de la Constitución Federal, del distrito federal y de los distintos estados, solo en lo concerniente a las facultades de los municipios en relación con la integración regional, si es que existiesen 
y con la competencia para firmar tratados, ya que esta última se relaciona con la cooperación y colaboración municipal con otras entidades para proveer al bienestar local. Finalmente trataremos de llegar a una conclusión acerca de la existencia de competencias municipales en este sentido y al alcance de las mismas.

\section{Organización político-administrativa del Brasil}

Desde 1889, año en el que se instauró la República, se adoptó la forma federativa de gobierno, siguiendo como modelo el constitucionalismo norteamericano, el cual también inspiró a la Constitución de la República Argentina, entre otros países de América Latina.

El Brasil es un Estado federal compuesto por distintos tipos de sujetos (Assoni Filho, 2008, p. 477). En primer lugar, existe la Unión Federal, que es la entidad federativa soberana encargada de representar la reunión de Estados miembros, el distrito federal y los municipios. Los estados federados son las instituciones típicas de la Federación, todos ellos autónomos. El distrito federal que, si bien no es un estado, ni tampoco un municipio, tiene las mismas competencias legislativas que ambos, pero se halla imposibilitado de subdividirse en Municipios. Por último, se encuentran los municipios, que poseen autonomía política, administrativa y financiera (Van Holthe, 2016).

El municipio brasilero se puede definir desde tres ejes (Lopez Mireilles, 1998, p. 118). Desde el punto de vista sociológico es un conjunto de personas que habitan un mismo territorio, poseen intereses comunes y se reúnen en sociedad para satisfacer sus necesidades individuales. Desde el punto de vista político es una entidad estatal de tercer grado, con atribuciones propias y gobierno autónomo. Por último, en el orden legal es una persona jurídica de derecho público interno.

Para algunos autores brasileros, no hay duda de que la constitución reformada ha transformado a los municipios en entidades verdaderamente autónomas y en este sentido en la arquitectura federativa idealizada por la Constitución de 1988, el municipio se convirtió en un miembro integrante de la Federación y logró obtener autonomía política, económica, legislativa, administrativa y organizacional (Herman Caggiano, 2007, p. 47). En algunos casos se hace hincapié en su autoorganización, la cual se expresa primordialmente en la elaboración de su propia ley orgánica (Cunha Chimenti, Capez, Rosa y Ferreira dos Santos, 2010, p. 221). Sin embargo, esta pretendida autonomía municipal es cuestionada en virtud de su efectiva puesta en práctica. Dentro de esta corriente algunos autores consideran que los municipios, a pesar de ser considerados autónomos por la Constitución de la República (artículo 18), no poseen autonomía constitucional en la misma dimensión que los estados y el Distrito Federal (Nilo de Castro, 2006, pp. 32-34). Los 
Municipios son divisiones de los Estados, no de la Unión. Por lo tanto, su creación, fusión, incorporación y desmembramiento dependen de la ley estatal, conforme los requisitos de la Constitución Federal.

\section{II.1. Constitución Federal}

La constitución brasilera de 1988(1), en su artículo 18, capítulo primero relativo a la organización político administrativa, establece que: "La organización político-administrativa de la República Federativa del Brasil comprende la Unión, los estados, el Distrito Federal y los municipios, todos autónomos, en los términos de esta Constitución". En consecuencia, no hay duda de que estamos ante la presencia de un Estado federal.

En el capítulo segundo relativo a los Estados federales, establece en su artículo 25 que: "Los estados se organizan y se rigen por las Constituciones y leyes que adopten, observando los principios de esta Constitución". Esta disposición es una confirmación del sistema federal de gobierno.

En relación con los municipios, la constitución nacional establece en el capítulo cuarto, artículo 29 que el municipio se regirá por una ley orgánica, la cual atenderá a los principios establecidos en la Constitución Federal y en la Constitución del respectivo Estado. Por su parte, el artículo 30 dispone que corresponde a los municipios legislar sobre asuntos de interés local, complementar la legislación federal y estatal en lo que fuere necesario, establecer y recaudar los tributos de su competencia. Finalmente, el artículo 32 prohíbe que el Distrito Federal pueda dividirse en municipios y afirma que se regirá por la ley orgánica que se dicte en consecuencia. El principio de subsidiariedad y solidaridad, es decir, la actuación del gobierno federal y de los gobiernos locales, tiene prevalencia por sobre los municipios, solo cuando estos últimos no pueden llevar a cabo con la debida eficiencia las políticas públicas que le fueren encargadas (Ferrari, 2014, p. 204).

\section{Competencia municipal para celebrar tratados y asociarse}

Al momento de analizar cada una de las constituciones estatales, hemos podido observar que la competencia de las entidades municipales para desarrollar esta actividad, ya sea que se trate de la firma de un acuerdo con otro municipio, estado o con el Estado Nacional, presenta diferencias bien marcadas. Por un lado, tenemos municipios con competencias que hemos denominado indirectas, en las cuales no existe una atribución directa de competencias en este sentido, pero que

(1) Constitución Federal Brasilera 1988. 
se deriva de la competencia de los distintos estados para celebrar acuerdos con los municipios. Por otro lado, existen municipios que guardan silencio al respecto, otros que otorgan competencia expresa y un cuarto grupo que se ocupan de la competencia de los municipios para asociarse con fines de interés común. A continuación, desarrollaremos un examen de las constituciones estatales agrupándolas de acuerdo con los distintos tipos de competencia explicados con anterioridad.

\section{III.1. Competencia indirecta}

Bajo este grupo incluimos a aquellas Constituciones estatales que otorgan competencia indirecta a los municipios para celebrar acuerdos. La competencia se origina en la facultad que le corresponde primariamente al estado para celebrar acuerdos o firmar tratados sobre determinados asuntos. Si bien no se establece expresamente que las entidades municipales tienen competencia para llevar a cabo los actos jurídicos mencionados, se puede considerar que esta facultad es la contracara de la competencia que poseen los Estados para concretar la firma de convenios o celebración de acuerdos con los municipios. Los objetivos de estos acuerdos se relacionan con la provisión de servicios, ejecución de leyes, protección de los derechos sociales consagrados en la Constitución federal, educación y asistencia técnico-financiera, entre otros.

La Constitución de Bahía(2) establece en el artículo 6 que el estado se divide en municipios, los cuales son considerados unidades político administrativas autónomas. Por su parte, el estado tiene competencia para celebrar convenios con la Unión, otros estados y municipios a través de la administración directa o indirecta, ya sea para la ejecución de sus leyes, servicios o decisiones por intermedio de funcionarios federales, estatales o municipales (artículo 8). Los municipios son caracterizados como unidades autónomas en el plano político, económico y financiero, que se rigen por sus leyes orgánicas, las cuales deben observar lo dispuesto en la Constitución federal y estatal (artículo 55). Finalmente, es importante destacar que tienen competencia para elaborar y promulgar su ley orgánica, ejecutar la política de desarrollo urbano, crear, organizar y suprimir distritos, observando la legislación estatal (artículo 59).

En el caso del estado de Sergipe, la constitución estatal autoriza la celebración de convenios con personas jurídicas de derecho público interno (artículo 7.9) (3). Se establece que tanto el planeamiento como la ejecución de las funciones públicas de interés común se efectuarán mediante concesión a entidad estatal o

(2) Constitución del Estado de Bahía, 05/10/1989. Última enmienda, No 14, 17/06/2010.

(3) Constitución del Estado de Sergipe, 5/10/1989. Última enmienda, № 36, 31/10/2005. 
municipal (artículo 11.3). Son considerados unidades territoriales dotadas de autonomía política, administrativa y financiera (artículo 12).

La constitución del estado de Mato Grosso do Sul dispone que el estado tiene competencia para celebrar convenios con la Unión o con los municipios para la ejecución, por funcionarios federales y municipales, de sus leyes, servicios o decisiones (artículo 8) (4). De la misma manera, el estado de Rio Grande do Norte resulta competente para celebrar convenios con la Unión, otros estados o municipios, para la ejecución de leyes, servicios o decisiones por empleados federales, estatales o municipales (artículo 18.4)(5). Los municipios ejercen, en su propio interés, todas las competencias no reservadas a la Unión o al estado (artículo 24). Con una redacción similar, el estado de Piauí otorga competencia al Estado para celebrar convenios con la Unión, con otros estados, con municipios, con reparticiones u órganos de la Administración indirecta, inclusive fundacional, para la ejecución de sus leyes, servicios o decisiones, por empleados federales, estatales o municipales (artículo 15) (6). Finalmente, el estado de Pará establece en la Constitución estatal (artículo 19)(7) la competencia para celebrar convenios con la Unión, con otros estados y con los municipios, dando conocimiento y remitiendo a la Asamblea Legislativa copias de su contenido, en el plazo de quince días, contado desde la fecha de su celebración. En muchos de los casos descriptos, la competencia del ente local se relaciona con la organización y mantenimiento de los servicios públicos, competencia que está expresamente reconocida por la Constitución Federal en su artículo 30 (Cavalcante Costa, 2017, p. 78).

\section{III.2. Silencio normativo}

Otras Constituciones estatales, a diferencia de las mencionadas con anterioridad, no contienen disposiciones expresas ni indirectas que prevean el otorgamiento de competencia municipal para celebrar tratados, convenios u otro tipo de acuerdos, ya sea con otros municipios, con el estado federal o con los estados federados. Este silencio normativo a nivel estatal no implica que ante la ausencia de norma expresa los municipios no puedan celebrar acuerdos para llevar a cabo acciones y tareas locales dentro del ámbito de su competencia de acuerdo con las cartas orgánicas municipales y las normas derivadas en su consecuencia, ya que, en la esfera legislativa, es competencia de los municipios, legislar sobre asuntos de

(4) Constitución del Estado de Mato Grosso do Sul, 5/10/1989. Última enmienda, No 51, 08/11/2011.

(5) Constitución del Estado de Rio Grande do Norte, 03/10/1989. Última enmienda, No 13, 15/07/2014.

(6) Constitución del Estado de Piauí, 05/10/1989. Última enmienda, № 41, 10/09/2013.

(7) Constitución del Estado de Pará, 05/10/1989. Última enmienda, No 51, 14/12/2011. 
interés local (artículo 30, inciso 1, Constitución Nacional de 1988) (Dias Marques da Cruz, 2006, p. 849). A continuación, señalamos las Constituciones de los Estados incluidos dentro de este grupo.

El artículo 1 de la Constitución de Acre(8) dispone que: "el estado de Acre con sus municipios, es parte integrante de la República Federativa de Brasil, ejerciendo en su territorio los poderes correspondientes a su autonomía y regulándose por esta constitución y las leyes que fuere a adoptar". El artículo 13 afirma que los municipios están dotados de autonomía política, administrativa y financiera en los términos asegurados por la Constitución Federal, por la Constitución estatal y por las respectivas leyes orgánicas. Por su parte, el artículo 22 describe la competencia de los municipios; a saber: legislar sobre asuntos de interés local, legislar supletoriamente en lo que correspondiere, establecer y recaudar tributos de su competencia, crear, organizar y suprimir distritos.

El estado de Ceará (9) dota a los municipios de competencia para legislar sobre asuntos de interés local, complementar la legislación federal y estatal, en lo que correspondiere, establecer y recaudar tributos de su competencia, crear, organizar y suprimir distritos (artículo 28). Similarmente, describe la competencia de los municipios la Constitución del estado de Espíritu Santo (artículo 28)(10), la cual comprende la facultad de legislar sobre asuntos de interés local, complementar la legislación federal y estatal en lo que correspondiere, establecer y recaudar tributos de su competencia, crear, organizar y suprimir distritos. Casi la misma redacción se encuentra en la Constitución del estado de Mato Grosso(11).

La Constitución del estado de São Paulo(12) se limita a consagrar la autonomía política, legislativa, administrativa y financiera (artículo 144) y prevé que el territorio estatal podrá ser dividido, total o parcialmente, en unidades regionales constituidas por agrupamientos de Municipios limítrofes, mediante ley complementaria, para integrar la organización o planeamiento y la ejecución de funciones públicas de interés común, atendiendo a las respectivas particularidades (artículo 153). Sigue este mismo modelo la Constitución de Roraima (13). Finalmente,

(8) Constitución del Estado de Acre, 03/10/1989. Última enmienda, No 48, 27/04/2017.

(9) Constitución del Estado de Ceará, 05/10/1989. Última enmienda, № 86, 16/02/2016.

(10) Constitución del Estado de Espíritu Santo, 05/10/1989. Última enmienda, No 108, 22/05/2017.

(11) Constitución del Estado de Mato Grosso, 05/10/1989. Última enmienda, No 35, 15/06/2005: "Los Municipios son dotados de competencia para legislar sobre asuntos de interés local, complementar la legislación federal y estatal en lo que correspondiere, establecer y recaudar tributos de su competencia" (artículo 112).

(12) Constitución del Estado de San Pablo, 05/10/1989. Última enmienda, No 36, 17/05/2012.

(13) Constitución del Estado de Roraima, 03/10/1989. Última enmienda, No 23, 07/07/2009: “La organización político administrativa del Estado comprende los Municipios, regidos por Leyes Orgá- 
el estado de Pernambuco(14) no se distancia de este tipo de redacciones, aunque agrega la existencia del Distrito Estatal de Fernando de Noroña (artículo 75).

\section{III.3. Competencia expresa}

Otro grupo de estados concede a los municipios competencias expresas para celebrar acuerdos o tratados con otras entidades para el cumplimiento de fines específicos y dentro del marco de sus atribuciones. Las modalidades que pueden presentar estos acuerdos dependen del tipo de entidad con la cual se celebre y del objeto que persiga el tratado. Se incluyen tratados con la Unión, con otros estados o con otros municipios para fines de interés común, ejecución de actos locales o educación, entre otros. Si bien es cierto que los gobiernos locales carecen de personería jurídica en el ámbito internacional, podemos observar que existen supuestos en los cuales ciertas cartas municipales otorgan competencia limitada para celebrar acuerdos (Hernández, 2000, p. 85). En el ámbito de la educación, los municipios brasileros ocupan un lugar central en relación con las políticas educativas a nivel nacional, ya que son las principales entidades federadas responsables de la creación de matrículas, tanto infantiles como de enseñanza básica (Loyola, 2017, p. 769).

Dentro de este grupo encontramos la Constitución del estado de Rio de Janeiro (15), cuyo artículo 76 faculta a los municipios mediante la aprobación de las respectivas cámaras municipales a formar consorcios intermunicipales para atender problemas específicos de sus miembros por el período de tiempo que los mismos determinen. En un sentido similar, la Constitución del estado de Amapá(16) afirma en su artículo 15 que los municipios podrán celebrar convenios con la Unión, el estado u otros municipios con el fin de ejecutar sus leyes, servicios o decisiones.

Los municipios, en el estado de Amazonas(17), poseen competencia para legislar sobre asuntos de interés local, complementar la legislación federal y estatal en lo que correspondiere, establecer y recaudar tributos de su competencia, crear, organizar y suprimir distritos y establecer consorcios entre sí (artículo 125). Por

nicas, observados los principios de la Constitución Federal y de la Constitución Estatal" (artículo 6); "La Ley Orgánica Municipal, por la cual se regirán los Municipios, será votada y promulgada por las Cámaras Municipales, observando los principios de la Constitución Federal y de la Constitución Estatal" (artículo 15).

(14) Constitución del Estado de Pernambuco, 05/10/1989. Última enmienda, No 41, 21/09/2017.

(15) Constitución del Estado de Rio de Janeiro, 05/10/1989. Última enmienda, No 53, 26/06/2012.

(16) Constitución del Estado de Amapá, 20/12/1991. Última enmienda, No 56, 03/05/2017.

(17) Constitución del Estado de Amazonas, 05/10/1989. Última enmienda, № 75, 26/12/2011. 
último, se dispone que podrán establecer consorcios para la realización de funciones, programas, proyectos y actividades de interés común (artículo 140).

En el caso del estado de Goiás, la Constitución estatal (18) dispone en su artículo 65 que los municipios tienen competencia para celebrar convenios y acuerdos con la Unión, los estados o el Distrito Federal, otros municipios y entidades de la administración directa o indirecta para la realización de sus actividades propias. A su vez, tienen especial competencia para celebrar consorcios públicos y convenios de cooperación con la Unión, los estados, el Distrito Federal y otros municipios en relación con la gestión asociada de servicios públicos (artículo 65, inciso 4). Dentro de esta línea, la Constitución del estado de Santa Catarina (19) expresa que las entidades municipales poseen competencia para crear asociaciones, consorcios y entidades intermunicipales para la realización de acciones, obras y servicios de interés común (artículo 114, inciso 4.3). La misma competencia para firmar convenios, contratos, acuerdos y otros instrumentos similares, queda establecida en la Constitución de Paraíba (20) (artículo 11.12). Resulta interesante destacar la disposición del artículo 204 de la Constitución del estado de Alagoas (21), la cual prevé que el estado y los municipios, en vistas al desarrollo de la enseñanza de $1^{\circ}$ y $2^{\circ}$ grado y erradicación del analfabetismo, podrán celebrar convenios con entidades de establecimientos de enseñanza, con previa autorización del poder legislativo.

En el caso del estado de Tocantins, la Constitución local(22) afirma que, para la obtención de sus objetivos, los municipios podrán organizarse en consorcios, cooperativas o asociaciones, mediante aprobación de sus Cámaras Municipales a propuesta de los respectivos prefectos (artículo 58.2). A su vez, las entidades municipales tienen competencia para celebrar convenios y acuerdos con la Unión, los estados, el Distrito Federal, otros municipios y sus entidades de la administración directa, indirecta o fundacional, para la realización de sus propias actividades (artículo 58.3). Los municipios en el Estado de Rondônia están facultados para realizar servicios y actividades de interés común, mediante convenios con entidades públicas o particulares a través de consorcios intermunicipales aprobados por las respectivas Cámaras, utilizando los medios e instrumentos adecuados para su ejecución (artículo 115)(23).

(18) Constitución del Estado de Goiás, 05/10/1989. Última enmienda, No 48, 04/07/2012.

(19) Constitución del Estado de Santa Catarina, 05/10/1989. Última enmienda, No 74, 05/07/2017.

(20) Constitución del Estado de Paraíba, 05/10/1989. Última enmienda, No 18, 09/03/2003.

(21) Constitución del Estado de Alagoas, 05/10/1989. Última enmienda, No 38, 13/05/2010.

(22) Constitución del Estado de Tocantins, 05/10/1989. Última enmienda, № 25, 21/12/2011.

(23) Constitución del Estado de Rondônia, 28/09/1989. Última enmienda, № 12, 7/2018. 
Finalmente, nos resta analizar dentro de este grupo, el Distrito Federal(24), cuyo asiento territorial lo constituye Brasilia. La ciudad detenta un doble status, es la capital de la República Federativa de Brasil y a su vez es la sede del gobierno del Distrito Federal (artículo 6). Posee autonomía política, administrativa y financiera de acuerdo con los principios constitucionales (artículo 1) y ejerce todas las competencias legislativas reservadas a los estados y municipios siempre que no le sean vedadas por la Constitución Federal (artículo 14). Es importante destacar que la Constitución local le atribuye competencia para celebrar y firmar consorcios, convenios, acuerdos y decisiones administrativas con la Unión, estados y municipios para la ejecución de sus leyes y servicios (artículo 15.8).

\section{III.4. Competencia para asociarse}

Un cuarto grupo de estados otorgan una competencia expresa a los municipios para asociarse en miras a la realización de intereses comunes, en particular para acciones vinculadas a la salud pública o concesiones de servicios públicos. Es posible afirmar que existe una tendencia global hacia la descentralización, lo que implica que los municipios asumen nuevas responsabilidades en materia de salud, educación, seguridad, asistencia social, ecología, promoción económica y desarrollo sustentable (Hernández, 2000a, p. 75). En lo concerniente a la política de salud, la Constitución nacional de 1988 universaliza el acceso a la salud básica, descentralizándose en su ejecución, lo que implicó la obligatoriedad atribuida a los municipios para cubrir aspectos relativos a esta política (Penalva Santos, 2011, p. 217).

En el estado de Mináis Gerais el municipio se encuentra dotado de autonomía política, administrativa y financiera, se organiza y rige por su Ley Orgánica (25) y demás leyes que adoptare con base en los principios de la Constitución de la República y de la Constitución Estatal (artículo 165, inciso 1). Según el artículo 165 inciso 2, uno de los objetivos prioritarios del municipio es la cooperación con la Unión y el estado y la asociación con otros municipios para la realización de intereses comunes. A su vez, el municipio tiene la facultad de asociarse con otros municipios del mismo complejo geoeconómico y social, mediante convenio previamente aprobado por la Cámara Municipal para la gestión bajo planeamiento de funciones públicas o servicios de interés común, de forma permanente o transitoria (artículo 181, inciso 1). En consecuencia, debe cooperar con la Unión y el Estado, en los términos del convenio o consorcio previamente aprobados por la Cámara Municipal, en la ejecución de servicios y obras de interés para el desarrollo local

(24) Constitución del Distrito Federal, 08/06/1993. Última enmienda, No 102, 07/2017.

(25) Constitución del Estado de Minais Gerais, 21/09/1993. Última enmienda, No 90, 12/07/2012. 
(artículo 181, inciso 2). De forma similar el estado de Rio Grande do Sul dota de autonomía política, administrativa y financiera a los municipios (26), y prevé que aquellos municipios que no poseyeren sistema propio de previsión y salud podrán vincularse al sistema de previsión estatal, en los términos de la ley o asociarse con otros Municipios (artículo 14). La Carta orgánica del estado de Paraná(27) prevé que los municipios podrán con anuencia y fiscalización de las respectivas Cámaras Municipales, teniendo en vista intereses mutuos, asociarse y conceder servicios públicos para utilización conjunta, a cualquier entidad con personalidad jurídica propia, dirección autónoma y finalidad específica (artículo 25).

Finalmente, encontramos dentro de este grupo, al estado de Maranhão, el cual dispone que el municipio es considerado una unidad territorial con autonomía política, administrativa y financiera, se organiza y se rige en los términos de la Constitución Federal, de la Constitución estatal y de la respectiva Ley Orgánica (28) (artículo 141). Los municipios podrán asociarse mediante convenios para explorar bajo planeamiento integrado y ejecución múltiple, los servicios de interés común, de forma permanente o periódica (artículo 146).

\section{El municipio como actor en la esfera internacional}

La actuación paradiplomática, además de traer ventajas para los que están directamente envueltos en el proceso, beneficia a la región, ya que aumenta su visibilidad y potencia su desarrollo. En este sentido, Mercociudades representa un cambio cualitativo en el fortalecimiento de las relaciones regionales a través del protagonismo de los actores sociales en la formulación de propuestas y por medio de la articulación de diferentes niveles de gestión pública. Las redes internacionales de ciudades constituyen un medio para realizar la inserción internacional de los gobiernos locales, y de esta manera poder incrementar la cooperación internacional descentralizada, la cual implica un proceso gradual de creación de redes de trabajo, solidaridad estratégica e intercambio de información. Estas actividades poseen un gran potencial para el avance de los procesos de integración (Mallmann y Clemente, 2016).

Como producto de la globalización y el surgimiento de los distintos procesos de integración, los municipios brasileros han intentado potenciar sus facultades para poder obtener beneficios económicos relacionados con el desarrollo, la industrialización y la cooperación internacional (Milani y Ribero, 2010, p. 23). Estas actividades conocidas como actividades paradiplomáticas se han venido desarrollando

(26) Constitución del Estado de Rio Grande do Sul, 03/10/1989. Última enmienda, No 65/2012.

(27) Constitución del Estado de Paraná, 03/10/1989. Última enmienda, No 31, 22/05//2012.

(28) Constitución del Estado de Maranhão, 05/10/1989. Última enmienda, № 66, 20/06//2012. 
desde 1980. De acuerdo con la legislación brasilera, las entidades municipales no encuentran una prohibición para la realización de actividades internacionales siempre y cuando se respeten los principios y lineamientos básicos que establece la Constitución Federal, ya que la regla general que establece el artículo 30 de la Constitución Nacional dispone que el Municipio es competente para decidir, dentro de sus funciones deliberativas y ejecutivas, todos los asuntos que versen sobre un interés exclusivamente local (Braz, 1994, p. 80). En otro sentido, el artículo 21 de la misma dispone que compete al Gobierno Federal mantener relaciones con otros Estados y participar en las organizaciones internacionales. Mencionaremos algunos ejemplos de cómo se han realizado actividades en el ámbito internacional por parte de los municipios:

- Creación de Asociaciones nacionales como la Confederación Nacional de Municipalidades.

- La aparición del Frente Nacional de Alcaldes.

- La creación de “Mercociudades" en 1995, en el ámbito del Mercosur.

- En 2005 se funda el Foro Brasileño de Relaciones Internacionales de las secretarías municipales.

- La aprobación de la legislación para constituir Consorcios Intermunicipales Fronterizos (CIF).

En muchos casos los municipios han llevado a cabo tareas de organización de seminarios, cursos de capacitación y formación profesional, publicación de guías y recomendaciones para lograr el desarrollo de proyectos internacionales. Para poder desarrollar estas tareas, los municipios crearon aéreas o puestos específicos que trabajan sobre el tema, como servicios administrativos sobre asuntos internacionales, un secretario o consejo bajo supervisión del secretario, entre otras. Podemos encontrar municipios con una estructura determinada encargada de las relaciones internacionales, como por ejemplo en las siguientes ciudades: Fortaleza (Secretariado de relaciones internacionales dependiente directamente del gobierno), Recife (Servicio de relaciones internacionales dependiente de secretariado), Belém (Asesor/Coordinador), Rio de Janeiro (Asesor/Coordinador), Belo Horizonte (Secretaría Adjunta de relaciones internacionales y Secretaría Municipal de desarrollo, Campinas (Secretariado municipal de relaciones internacionales), Santos (Asesor/Coordinador) Soracaba (Servicio de relaciones internacionales dependiente de secretariado), Santo André (Servicio de relaciones internacionales dependiente de secretariado). Municipios que ejercen actividades paradiplomáticas sin contar con ningún tipo de estructura formal: Corumbá, Cuiabá, Olinda, Natal, Manaus. Municipalidades que no ejercen actividades paradiplomáticas y 
no cuentan con ningún tipo de estructura formal encargada de ello: Campo Grande, Maceió, Aracajú, Rio Preto, Londrina, Uruguaiana, Blumenau. El primer grupo de municipios confirma que las regiones más ricas del país poseen la mayor parte de municipios con actividades paradiplomáticas, correspondiendo a las regiones Sur y Sudeste. El segundo grupo concentra muchos municipios que desarrollan proyectos informales y menos visibles, la mayor parte de ellos en la región del Noroeste.

Las municipalidades que tienen una estructura formal encargada de las relaciones internacionales desarrollan fundamentalmente tres tipos de actividades paradiplomáticas:

- Participación en redes trasnacionales como Mercociudades.

- Participación en congresos y acontecimientos internacionales.

- Acuerdos de hermanamiento entre ciudades, pertenencia a asociaciones internacionales y establecimiento de redes regionales y globales.

- Cooperación transfronteriza. Un ejemplo de este tipo de cooperación puede encontrarse en ciertos tratados firmados entre Brasil y Uruguay a partir de 2002 sobre permiso de residencia, estudio y trabajo para nacionales fronterizos. Para cumplir con los objetivos se crearon instituciones transfronterizas que incluyen dos comisiones binacionales para el tratamiento del río Quaraí y la laguna de Mirim, recursos hídricos, problemas de contaminación, desarrollo agrícola, comunicaciones y transporte. Surgieron comités de frontera, constituidos por representantes de organismos locales y organizaciones sociales de los municipios para tratar temas de relaciones entre las provincias, estados y departamentos de los países vecinos. Los intercambios incluyen gobiernos locales, universidades, productos rurales, organizaciones culturales y movimientos sociales (Mallmann y Clemente, 2016).

En las regiones más ricas del país se concentran la mayoría de las municipalidades que realizan actividades para diplomáticas (Milani y Ribero, 2010, p. 40). El $76 \%$ de las 51 municipalidades corresponden a las regiones del Sur y el Sudoeste. En el caso de Macapá (Amapá), el municipio ha firmado una serie de proyectos de cooperación bilateral con Cayenne en la Guyana francesa en 1990. Otras dos ciudades que deben ser destacadas son Uberlandia y Olinda, ya que ambas poseen relaciones con la Cámara de Comercio de Estados Unidos y ciertos programas culturales de la UNESCO, respectivamente (De Munho Colesanti y Rodrigues Moreira Campos, 2012, p. 321). En el ámbito cultural, la protección comprende documentos, obras y otros bienes de valor histórico, artístico y cultural, monumentos, 
paisajes naturales y sitios arqueológicos. Los principales países que han establecido asociaciones con dichas Municipalidades son Francia, España, Portugal e Italia, así como China y Japón. Por otro lado, entre los años 2004 y 2007 con la llegada de Lula da Silva a la presidencia y el otorgamiento de mayor atención a las estrategias de internacionalización, se ha creado el mayor número de estructuras formales que se ocupan de asuntos internacionales a nivel municipal. A su vez, en el ámbito regional, en el marco del Mercosur encontramos un ejemplo de actividad paradiplomática en el Foro de Consulta de Municipalidades, Estados federados, Provincias y Departamentos del Mercosur, que fue creado por la decisión del Consejo del Mercado común No 41/04 y comenzó a funcionar en el año 2007.

Este sustituyó a la Reunión Especializada de Municipios e Intendencias y tiene como objetivo principal la coordinación de políticas para promover el bienestar y mejorar la calidad de vida de los habitantes de los Municipios, pudiendo formular recomendaciones por intermedio del Grupo del Mercado Común. Está formado por un Comité de los Municipios y un Comité de los Estados Federados, Provincias y Departamentos. El espacio no ha realizado aportes significativos, siendo el más relevante el último Plan de acción (2016-2017) a fin de orientar acciones coordinadas y sistematizadas bajo cuatro ejes: relacionamiento y cooperación, ciudadanía regional, integración productiva e integración fronteriza.

Es posible establecer un orden cronológico de las organizaciones que buscan intensificar las relaciones entre ciudades y municipios, así encontramos Eurocidades, establecida en 1989, Mercociudades, creada en 1995, Cities Alliances (1999), organización ligada a HABITAT/ONU y la red CGLU (Ciudades y Gobiernos locales Unidos) en 2004 (Mallmann y Clemente, 2016). El caso del Municipio de San Pablo merece una mención en particular. Durante el período comprendido entre los años 1989-1992, el primer órgano creado para encargarse de la acción internacional de la ciudad fue la Asesoría de Relaciones Internacionales, cuyas actividades iniciales tenían como objetivo el financiamiento internacional, la elaboración de proyectos, la cooperación tecnológica, el intercambio de experiencias y la realización de eventos internacionales. En 1986 se firma un Acuerdo de Cooperación Técnica y Económica con la ciudad de Toronto, como uno de los acontecimientos más relevantes. En el período 2001-2004 se crea la Secretaría Municipal de Relaciones Internacionales. A partir de este momento es posible observar un avance institucional y una mejor gestión de las políticas municipales a nivel internacional, dónde se destaca la participación activa en la red de Mercociudades, y Cities Alliances (Vigevani y Figuereido Prato, 2010, pp. 42-46).

Finalmente, debemos mencionar que las principales ventajas que se obtienen de la actividad paradiplomática por parte de los municipios son la cooperación técnica, el reconocimiento nacional, la atracción de inversiones, la toma 
de consciencia de la relevancia de los asuntos internacionales a nivel local y el intercambio de experiencias con actores internacionales. A su vez, beneficia a la región, ya que aumenta su visibilidad y potencia su desarrollo. Mercociudades representa un cambio cualitativo en el fortalecimiento de las relaciones regionales a través del protagonismo de los actores sociales en la formulación de propuestas y por medio de la articulación de diferentes niveles de gestión pública (Mallmann, 2016).

Es importante señalar que en las actividades paradiplomáticas se encuentran diferencias entre los Estados federales y los unitarios. Dentro de los primeros, donde se ubica Brasil, se advierten mayores niveles de autonomía en la gestión internacional. Resulta necesario destacar que el proceso de integración del Mercosur ha tenido una influencia positiva en este sentido, ya que se ha transferido a los entes locales la posibilidad de tomar decisiones sobre formas, vínculos e instrumentos tendientes a mejorar el desarrollo y, de esta manera, utilizar las ventajas obtenidas a partir de una mayor inserción internacional. Dentro de las ventajas de la paradiplomacia podemos mencionar también la ausencia de bagaje diplomático y una mayor flexibilidad en el diseño de planes (Bernal Meza, 2015). Sin embargo, es importante destacar el hecho de que la posible falta de conexión política entre el gobierno federal y el local puede llevar a crear problemas en la coordinación y desarrollo de políticas comunes. Al existir un número relevante de municipios que lleva a cabo tareas de cooperación internacional de forma aislada, sin planificación, ni plan estratégico, esto puede provocar el surgimiento de incoherencias a largo plazo.

En cuanto a los desafíos, resulta importante señalar que no todas las regiones están en las mismas condiciones para constituirse en el pilar del desarrollo local. Se enfrentan a la oposición de ciudades cercanas que pueden presentar cierta resistencia. La implementación de las políticas específicas se encuentra afectada por las diferencias entre ciudad y región dentro de un mismo país. En este sentido, la paradiplomacia no es solo un instrumento sino también un desafío político en relación con el Estado central, para lograr que los municipios se involucren en la "alta política" como actores independientes de las relaciones internacionales (Bernal Meza, 2015).

\section{Conclusión}

Luego de haber analizado la Constitución Federal y las distintas Constituciones estatales de la República del Brasil, incluyendo la Ley Orgánica del Distrito Federal, es posible determinar la competencia acordada a los estados y a los municipios en el Derecho público brasilero. En primer lugar, la Constitución Federal establece la autonomía estatal al autorizar que se rijan por sus propias instituciones, 
garantizando una autonomía político-administrativa dentro del ámbito de sus competencias y respetando los principios y directrices consagrados en la Constitución Federal. A su vez, también reconoce la autonomía municipal, la cual es confirmada por cada una de las constituciones estatales.

Al estudiar las diferentes constituciones estatales, podemos observar que algunas de ellas no hacen casi referencia a la competencia de los Municipios ni a la posibilidad de que se les permita celebrar acuerdos o convenios con la Estado Federal (Unión), otros Estados o Municipios como por ejemplo las Constituciones de Roraima, Río Grande del Norte y San Pablo, mientras que en otros casos se destacan Constituciones que desarrollan ampliamente el ámbito de competencias y estatus municipal. Todo esto, sin perjuicio de lo que establezcan en cada cado caso las leyes orgánicas municipales. De todas maneras, en ningún caso se menciona en las constituciones estatales la posibilidad de que los municipios celebren acuerdos de carácter internacional o relacionados con la integración regional, entendida esta última como el conjunto de relaciones entre los Estados, y entre estos y organismos internacionales, del cual surgen normas y actos jurídicos con el objeto de potenciar la cooperación para la obtención de fines propuestos y mejorar las relaciones reciprocas para fortalecer su posición conjunta frente a Estados que son ajenos al grupo formado (Pizzolo, 2010). A pesar de esta ausencia de normas específicas, los municipios constituyen un elemento fundamental en los sistemas de integración regional. Esto es así, ya que como hemos destacado con anterioridad, son las entidades mínimas que tienen el contacto más directo con la ciudadanía y las instituciones locales que desarrollan actividades diarias cercanas a la población. Son los municipios, a través de sus instituciones, los que reciben las quejas y pedidos de solución de problemas por parte de los habitantes que allí residen. A través de las políticas que la Nación desarrolla, impulsadas desde las autoridades de cada uno de los Estados, los Municipios pueden desarrollar en el ámbito de sus competencias locales diversas acciones que se insertan dentro de políticas propias de la integración regional, como quedó demostrado al analizar las actividades para diplomáticas de ciertos municipios, y que contribuyen al fin último de la integración, que consiste en modificar las condiciones de vida de los pueblos y acercar las autoridades locales a las distintas instituciones surgidas de los procesos de integración.

\section{Bibliografía}

Assoni Filho, S. (2008). Autonomia financiera local e democracia. Revista da Faculdade de Direito da Universidade de São Paulo, vol. 103 (pp. 475-499).

Braz, P. (1994). Direito Municipal na Constituição. Doutrina, prática e legislação. $1^{\circ}$ ed. São Pablo: Levraria de Direito. 
Bernal Meza, R. (2015). Paradiplomacia y regionalismo en situación de relaciones políticas en conflicto: El caso de Chile y Bolivia. Revista de Ciencia Política, volumen 35, № 3 (pp. 605-627).

Cavalcante Costa, Z. P. (2017). Brasil, el régimen jurídico Municipal. Instituto de Investigaciones Jurídicas, Universidad Nacional Autónoma de México (UNAM). Recuperado de http://biblio.juridicas.unam.mx/libros/6/2545/7.pdf [Fecha de consulta 03/25/2019].

Cunha Chimenti, R.; Capez, F.; Rosa, M. F. E. y Ferreita dos Santos, M. (2010). Curso de Direito Constitucional. $7^{\circ}$ ed. São Pablo: Saraiva.

Dias Marques da Cruz, G. (2006). Aspectos do controle de constitucionalidade de leis municipais. Revista da Faculdade de Direito da Universidade de São Paulo, vol. 101 (pp. 841-870).

De Munho Colesanti, M. T. y Rodrigues Moreira Campos, S. (2012). A tutela do patrimônio cultural e o muncípio de Uberlândia-MG. Revista da Faculdade de Direito de Uberlândia, vol. 40 (pp. 321-337).

Ferrari, R. M. M. N. (2014). Autonomía municipal no Estado federal brasileiro. Revista Eurolatinoamericana de Derecho Administrativo, volumen 1, o 2 (pp. 199-208). Recuperado de https://bibliotecavirtual.unl.edu.ar/publicaciones/ index.php/Redoeda/article/view/4623/7027 [Fecha de consulta 20/03/2019].

Herman Caggiano, M. (2007). O Município no Marco da Federação: Uma radiografia da questão atinente à confiança legítima en Direito Administrativo Municipal. Temas fundamentais e atuais. Academia Paulista de Letras Jurídicas / Centro de Extensión Universitario. Buenos Aires: Gobierno de la Ciudad Autónoma de Buenos Aires, Magister Editorial.

Hernández, A. M. (2000). Integración y Globalización. Buenos Aires: Depalma.

Lopez Mireilles, H. (1998). Direito Municipal Brasileiro. 10a ed. San Pablo: Malheiros Editores.

Loyola, P. (2017). Autonomía municipal e interdependencia deferativa: uma análise sobre as mudanças ocorridas no acesso e nos gastos em educação no Brasil (2000-2014). Educ. Soc., vol. 38, № 140 (pp. 767-790).

Mallmann, M. I. y Clemente, I. (2016). Transnacionalismo, paradiplomacia e integração: o caso do Brasil e Uruguai. Civitas, vol. 16, No 3 (pp. 417-436).

Milani, C. R. S. y Ribeiro, M. C. M. (2010). Para diplomacia y proyección internacional de las ciudades brasileñas: la elaboración del concepto de "gestión 
internacional local. Revista Geopolíticas, № 1 (pp. 23-40). Recuperado de http:// www.paradiplomacia.org/upload/downloads/5b8bf0e006b7b24cb7e809b3a812 30d2paradiplomacia\%20y\%20proyecci\%C3\%B3n\%20internacional.pdf [Fecha de consulta 23/03/2017].

Nilo de Castro, J. (2006). Direito Municipal Positivo. $6^{\text {a }}$ ed. Belo Horizonte: Del Rey.

Penalva Santos, A. (2011). Autonomía municipal no contexto federativo brasileiro. Revista Paranaense de Desenvolvimento, No 120 (pp. 209-230). Recuperado de file://C:/Users/mcanepa/Downloads/Dialnet-AutonomiaMunicipalNoContextoFederativoBrasileiro-3990148.pdf [Fecha de consulta 01/03/2019].

Pizzolo, C. (2002). Globalización e Integración Regional: Ensayo de una Teoría General. Buenos Aires: Ediar.

Van Holthe, L. (2016). Direito Constitucional. Salvador: JusPODIVM.

Vigevani, T. y Figuereido Prado, D. (2010). Acoes y Problemas da Paradiplomacia no Brasil. Relacoes Internacionais: Polaridades e novos/velhos temas emergentes. Marília: UNESP.

\section{Legislación}

Constitución del Distrito Federal, 08/06/1993. Última enmienda No 102, 07/2017.

Constitución del Estado de Acre, 03/10/1989. Última enmienda № 48, 27/04/2017.

Constitución del Estado de Alagoas, 05/10/1989. Última enmienda No 38, 13/05/2010.

Constitución del Estado de Amapá, 20/12/1991. Última enmienda No 56, 03/05/2017.

Constitución del Estado de Amazonas, 05/10/1989. Última enmienda № 75, 26/12/2011.

Constitución del Estado de Bahía, 05/10/1989. Última enmienda No 14, 17/06/2010.

Constitución del Estado de Ceará, 05/10/1989. Última enmienda No 86, 16/02/2016. 
Constitución del Estado de Espíritu Santo, 05/10/1989. Última enmienda No $108,22 / 05 / 2017$.

Constitución del Estado de Goiás, 05/10/1989. Última enmienda № 48, 04/07/2012.

Constitución del Estado de Maranhão, 05/10/1989. Última enmienda № 66, 20/06/2012.

Constitución del Estado de Mato Grosso, 05/10/1989. Última enmienda № 35, 15/06/2005.

Constitución del Estado de Mato Grosso do Sul, 05/10/1989. Última enmienda No $51,08 / 11 / 2011$.

Constitución del Estado de Minais Gerais, 21/09/1993. Última enmienda № 90, $12 / 07 / 2012$.

Constitución del Estado de Pará, 05/10/1989. Última enmienda No 51, $14 / 12 / 2011$.

Constitución del Estado de Paraná, 03/10/1989. Última enmienda № 31, $22 / 05 / / 2012$.

Constitución del Estado de Paraíba, 05/10/1989. Última enmienda № 18, 09/03/2003.

Constitución del Estado de Pernambuco, 05/10/1989. Última enmienda № 41, $21 / 09 / 2017$.

Constitución del Estado de Piauí, 05/10/1989. Última enmienda No 41, 10/09/2013.

Constitución del Estado de Rio Grande do Norte, 03/10/1989. Última enmienda No $13,15 / 07 / 2014$.

Constitución del Estado de Rio Grande do Sul, 03/10/1989. Última enmienda № $65 / 2012$.

Constitución del Estado de Rio de Janeiro, 05/10/1989. Última enmienda № 53, 26/06/2012.

Constitución del Estado de Rondônia, 28/09/1989. Última enmienda No $127 / 2018$. 
Constitución del Estado de Roraima, 03/10/1989. Última enmienda № 23, 07/07/2009.

Constitución del Estado de Santa Catarina, 05/10/1989. Última enmienda No $74,05 / 07 / 2017$.

Constitución del Estado de San Pablo, 05/10/1989. Última enmienda No 36, 17/05/2012.

Constitución del Estado de Sergipe, 05/10/1989. Última enmienda № 36, $31 / 10 / 2005$.

Constitución del Estado de Tocantins, 05/10/1989. Última enmienda № 25, 21/12/2011.

Constitución Federal Brasilera, 1988.

Fecha de recepción: 28-03-2019

Fecha de recepción: 22-07-2019 